\title{
Efecto del uso de protectores puerto desinfectantes para la disminución de las bacteriemias asociadas a catéteres venosos centrales ${ }^{1}$
}

\author{
Candy Guiselle López Navarro ${ }^{2}$, Helder Gabriel Noguera Mena ${ }^{3}$, María Valeria Barboza Cascante ${ }^{4}$, Jose Manuel \\ Ramírez Alvarado ${ }^{5}$, Guiselle Orozco Valverde ${ }^{6}$, William Gerardo Ibarra Sequeira ${ }^{7}$
}

Institución: Caja Costarricense de Seguro Social

\section{RESUMEN}

Identificar el efecto del uso de protectores puerto desinfectantes en los conectores sin aguja en la disminución de las bacteriemias asociadas a catéter venoso central. Se realizó una revisión rápida de la literatura a través de una búsqueda de artículos en idiomas inglés y español en Pubmed, Medline, Cochrane Library y Science Direct, de diciembre del año 2018 a febrero del año 2019. Esta revisión se centró en identificar ensayos: clínicos aleatorizados, cohorte longitudinal, revisiones sistemáticas y meta-análisis. Los criterios de inclusión fueron: usuarios hospitalizados, desinfección pasiva con protectores puerto desinfectantes y reporte de disminución de las bacteriemias asociadas a catéter venoso central con su uso. Un total de 2479 artículos se identificaron como potencialmente relevantes; después de eliminar los duplicados, quedaron 1622 artículos, los cuales fueron evaluados según título y resumen. Posteriormente, 59 artículos fueron analizados en texto completo; se seleccionaron 3 artículos correspondientes a tres revisiones sistemáticas, de las cuales dos realizaron metaanálisis. La evidencia disponible sugiere que estudios no aleatorizados han demostrado que el uso de los protectores puerto desinfectantes con alcohol isopropílico al 70\% en los conectores sin aguja, puede generar una reducción de las bacteriemias asociadas al catéter venoso central y podría considerarse como una medida costo efectiva; no obstante, se requieren estudios aleatorizados que confirmen estos resultados.

Palabras clave: Antiinfecciosos; Bacteriemia; Catéter-Venoso-Central; Control-de-Infecciones; Desinfección.

DOI 10.15517/revenf.v0i38.38531

${ }^{1}$ Fecha de recepción: 02 de agosto del 2019

${ }^{3}$ Enfermero. Hospital Dr. Rafael Ángel Calderón Guardia. Costa Rica. Correo electrónico: hy_noguera@yahoo.com

${ }^{4}$ Enfermera. Hospital Dr. Rafael Ángel Calderón Guardia. Costa Rica. Correo electrónico: valbarc@gmail.com

${ }^{5}$ Enfermero. Hospital Dr. Rafael Ángel Calderón Guardia. Costa Rica. Correo electrónico: jmraenf@gmail.com

${ }^{6}$ Supervisora de Enfermería. Hospital Dr. Rafael Ángel Calderón Guardia. Costa Rica. Correo electrónico: guiselleoro@gmail.com

${ }^{7}$ Enfermero. Hospital Dr. Rafael Ángel Calderón Guardia. Costa Rica. Correo electrónico: will-i-s@,hotmail.com 


\title{
Effect of the use of antiseptic barrier caps for the reduction of bacteremia associated with central venous catheters ${ }^{1}$
}

\author{
Candy Guiselle López Navarro ${ }^{2}$, Helder Gabriel Noguera Mena ${ }^{3}$, María Valeria Barboza Cascante ${ }^{4}$, Jose Manuel \\ Ramírez Alvarado $^{5}$, Guiselle Orozco Valverde ${ }^{6}$, William Gerardo Ibarra Sequeira ${ }^{7}$
}

Institution: Costa Rican Social Security

\begin{abstract}
Identify the effect of the use of disinfectant port protectors on needleless connectors in the reduction of bacteraemias associated with central venous catheters. A quick review of the literature was carried out through a search of articles in English and Spanish in Pubmed, Medline, Cochrane Library and Science Direct; from December 2018 to February 2019. It focused on identifying randomized clinical trials, longitudinal cohort, systematic reviews and meta-analysis. The inclusion criteria were: hospitalized users, passive disinfection with disinfectant port protectors and report of decrease in bacteraemias associated with central venous catheter with its use. A total of 2479 articles were identified as potentially relevant, after eliminating duplicates, 1622 articles were evaluated according to inclusion criteria were: hospitalized users, passive disinfection with disinfectant port protectors and report of decrease in bacteraemias associated with central venous catheter with its use. the available evidence suggests that non-randomized studies have shown that the use of disinfectant port protectors with 70\% isopropyl alcohol in needleless connectors can lead to a reduction in bacteraemias associated with central venous catheters and could be considered as a cost measure. effective, however, randomized studies are required to confirm these results.
\end{abstract}

Keywords: Anti-infective-Agents; Bacteremia; Central-Venous-Catheter; Disinfection; Infection-Control.

DOI 10.15517/revenf.v0i38.38531

${ }^{1}$ Date of receipt: August 02, 2019

Date of acceptance: December 02, 2019

${ }^{2}$ Nurse. Dr. Rafael Ángel Calderón Guardia Hospital. Costa Rica. E-mail: clopez20@gmail.com

${ }^{3}$ Nurse. Dr. Rafael Ángel Calderón Guardia Hospital. Costa Rica. E-mail: hg_noguera@yahoo.com

${ }^{4}$ Nurse. Dr. Rafael Ángel Calderón Guardia Hospital. Costa Rica. E-mail: valbarc@gmail.com

${ }^{5}$ Nurse. Dr. Rafael Ángel Calderón Guardia Hospital. Costa Rica. E-mail: jmraenf@gmail.com

${ }^{6}$ Nursing Supervisor. Dr. Rafael Ángel Calderón Guardia Hospital. Costa Rica. E-mail: guiselleoro@gmail.com

${ }^{7}$ Nurse. Dr. Rafael Ángel Calderón Guardia Hospital. Costa Rica. E-mail: will-i-s@,hotmail.com 


\title{
Efeito do uso de protetores desinfetantes portuários para a redução da bacteremia associada a cateteres venosos centrais ${ }^{1}$
}

\author{
Candy Guiselle López Navarro ${ }^{2}$, Helder Gabriel Noguera Mena ${ }^{3}$, María Valeria Barboza Cascante ${ }^{4}$, Jose Manuel \\ Ramírez Alvarado $^{5}$, Guiselle Orozco Valverde ${ }^{6}$, William Gerardo Ibarra Sequeira ${ }^{7}$
}

Instituição: Segurança Social da Costa Rica

\section{RESUMO}

Identificar o efeito do uso de protetores de porta desinfetantes nos conectores sem agulha na redução de bacteremias associadas aos cateteres venosos centrais. Uma rápida revisão da literatura foi realizada através de uma pesquisa de artigos em inglês e espanhol no Pubmed, Medline, Cochrane Library e Science Direct; de dezembro de 2018 a fevereiro de 2019. Concentrou-se na identificação de ensaios clínicos randomizados, coorte longitudinal, revisões sistemáticas e metanálise. Os critérios de inclusão foram: usuários hospitalizados, desinfecção passiva com protetores de porta desinfetantes e relato de diminuição de bacteremias associadas ao cateter venoso central com seu uso. Um total de 2479 artigos foi identificado como potencialmente relevante; após eliminação de duplicatas, 1622 artigos foram avaliados de acordo com o título e o resumo, depois 59 artigos foram analisados em texto completo, foram selecionados 3 artigos correspondentes a três revisões sistemáticas, dos quais dois realizaram meta-análise. As evidências disponíveis sugerem que estudos não randomizados demonstraram que o uso de protetores de porta desinfetantes com álcool isopropílico a $70 \%$ em conectores sem agulha pode levar a uma redução nas bacteremias associadas aos cateteres venosos centrais e pode ser considerado como uma medida de custo. estudos eficazes, no entanto, são necessários para confirmar esses resultados.

Palavras-chave: Anti-infecciosos; Bacteremia; Cateteres-Venosos-Centrais; Controle-de-Infecção; Desinfecção.

DOI 10.15517/revenf.v0i38.38531

${ }^{1}$ Data de recepção: 02 de agosto de 2019

${ }^{2}$ Enfermeira. Hospital Dr. Rafael Ángel Calderón Guardia. Costa Rica. Correio eletrônico: clopez20@gmail.com

${ }^{3}$ Enfermeiro. Hospital Dr. Rafael Ángel Calderón Guardia. Costa Rica. Correio eletrônico: hy_noguera@yahoo.com

${ }^{4}$ Enfermeira. Hospital Dr. Rafael Ángel Calderón Guardia. Costa Rica. Correio eletrônico: valbarc@gmail.com

${ }^{5}$ Enfermeiro. Hospital Dr. Rafael Ángel Calderón Guardia. Costa Rica. Correio eletrônico: jmraenf@gmail.com

${ }^{6}$ Supervisor de Enfermagem. Hospital Dr. Rafael Ángel Calderón Guardia. Costa Rica. Correio eletrônico: guiselleoro@gmail.com

${ }^{7}$ Enfermeiro. Hospital Dr. Rafael Ángel Calderón Guardia. Costa Rica. Correio eletrônico: will-i-s@hotmail.com 


\section{INTRODUCCIÓN}

Los cambios en los escenarios sanitarios, la implementación de avances tecnológicos relacionados con los cuidados para la salud y las trasformaciones paradigmáticas en torno a la atención de las personas, han tenido influencia en el cambio de los factores de riesgo para el desarrollo de las Infecciones Asociadas a la Atención en Salud (IAAS).

Las necesidades de monitorización invasiva o de accesos vasculares para tratamientos de las personas hospitalizadas, se traducen, muy a menudo, a la colocación de dispositivos médicos como los catéteres venosos de acceso central ${ }^{1,2}$. Se estima que entre un $7 \%$ a un $10 \%$ de las personas que se encuentran hospitalizadas llegan a requerirlos $^{3,4}$. Por tanto, una mayor demanda en su uso ha significado un incremento en el riesgo de desarrollar Bacteriemias Asociadas al Catéter Venoso Central (BACVC) $)^{5}$ En este sentido, un cuidado básico asociado con su prevención es la desinfección, tanto del sitio de inserción antes de colocar el catéter, como de los puertos de acceso mientras se use el dispositivo ${ }^{6}$.

La meta básica de eliminar o disminuir, tanto como sea posible, las BACVC es una de las mayores aspiraciones de los programas para la prevención de $\mathrm{IAAS}^{6}$. Dicha situación no es de extrañar si se toma en cuenta que es una de las infecciones que ocurre con mayor frecuencia durante la atención en salud de las personas ${ }^{7,8}$ y que se encuentra asociada con: el incremento de la morbi-mortalidad, los días de hospitalización y los costos de atención ${ }^{9}$.

Se estima que las tasas de incidencia de las BACVC en países desarrollados rondan los 3,5 casos por 1.000 días de dispositivo, mientras que en aquellos en vías de desarrollo es de 12,2 BACVC cada 1.000 días catéter ${ }^{10}$. El uso de listas de cotejo - que reúnen una serie de técnicas e intervenciones recomendadas por la evidencia para la correcta inserción de los catéteres centrales y sus cuidados-ha sido una de las estrategias utilizadas para reducirlas en los centros hospitalarios ${ }^{11}$.

Los puntos de acceso intravenoso de estos dispositivos, usualmente cubiertos por conectores sin aguja (CSA), constituyen uno de los focos de atención dentro de las listas mencionadas previamente; puesto que su continuo uso para la administración de medicamentos o hemocomponentes, aumenta el riesgo de contaminación y eventual infección $^{12}$. Su implementación, más allá de la disminución de los accidentes relacionados con agujas en personal de salud, fue avalada en numerosos estudios por facilitar la técnica aséptica y disminuir los tiempos de manipulación; así como, la práctica de dejar abiertos los puertos de acceso intravenoso ${ }^{13}$.

La desinfección apropiada de los CSA constituye una estrategia primordial para prevenir la BACVC, según el Centro para el Control y la Prevención de las enfermedades de los Estados Unidos de América ${ }^{6}$. Pues, una inadecuada técnica de desinfección aumenta el riesgo de bacteriemias al permitir el ingreso directo de microorganismos al sistema circulatorio ${ }^{14}$.

En este sentido, dos variables sencillas del procedimiento de desinfección, el tiempo y la fricción, han sido reconocidas por su trascendencia. Sin embargo, no existe actualmente un consenso en torno al tiempo necesario de fricción para garantizar la desinfección ${ }^{12}$, con la meta de eliminar o disminuir tanto como sea posible las BACVC. Sumado a lo anterior, existen argumentos válidos que reconocen la dificultad para ejecutar 
adecuadamente esta técnica, dada la alta carga laboral que viven las enfermeras y enfermeros en los entornos clínicos $^{15}$.

Cabe mencionar que un estudio in vitro realizado en el 2006 recomendó el uso de los CSA para los puertos de acceso intravenoso en los catéteres centrales. Además, evidenció que el uso de alcohol al 70\% no era suficiente contra la contaminación microbiana ${ }^{16}$. Adicionalmente, la literatura recomienda el uso de protectores con solución desinfectante sobre los CSA, para disminuir su contaminación y, por ende, las BACVC ${ }^{17}$. Otro estudio de tipo cuasi-experimental realizado en el 2014, concluyó que existe una relación entre el uso de protectores con solución desinfectante sobre los CSA y la reducción de las $\mathrm{BACVC}^{12}$.

Asimismo, se cree que antes de que fueran introducidos los conectores libres de aguja, el personal de salud sabía intuitivamente que debía desinfectar los puertos de acceso venoso antes de accederlos con el uso de agujas. Sin embargo, en la actualidad, algunos estudios señalan que las tasas de cumplimiento de desinfección de los puertos de accesos venosos pueden ser tan bajas como un $10 \%{ }^{18}$; lo cual constituye un porcentaje considerable que juega en contra de las estrategias sanitarias para la prevención de las BACVC.

El objetivo de la presente revisión se centró en analizar cuál es la mejor evidencia científica disponible respecto al uso de los protectores puerto desinfectantes en los conectores sin aguja, para la disminución de las bacteriemias asociadas a catéteres venosos centrales. Lo anterior debido a que, en los escenarios hospitalarios, la alta demanda de trabajo juega en contra de una correcta aplicación de la técnica de desinfección activa de los CSA que se colocan en los catéteres venosos centrales (CVC) y, además, a causa de la gran importancia de las BACVC en el entorno, como una de las principales IAAS.

\section{Pregunta de investigación}

La pregunta de revisión es la siguiente: ¿Cuál es el efecto del uso de protectores puerto desinfectantes en los conectores sin aguja, para la disminución de las bacteriemias asociadas a catéteres venosos centrales en pacientes hospitalizados?

\section{Resultados secundarios}

1. ¿Cuál es el agente desinfectante de uso más común en la desinfección pasiva de los puertos de acceso de los catéteres venosos centrales?

2. ¿Cuál es la efectividad del uso de los protectores puertos desinfectantes en los conectores sin aguja de los catéteres venosos centrales en la disminución de los costos económicos asociados a la BACVC?

\section{MATERIALES Y MÉTODOS}

Esta revisión se desarrolló con base en la Guía Breve para Elaborar Evaluación Rápida de la Evidencia de CIEBE-CR, la cual establece 8 pasos: 1. Elaboración de los antecedentes, 2. Establecimiento de la pregunta REA, 3. Definición de parámetros de búsqueda, 4. Identificación de los sesgos, 5. Planeamiento y ejecución de la búsqueda, 6. Análisis de la calidad del artículo, 7. Síntesis de la evidencia, 8. Resultados de la revisión. 
Tabla 1. Pregunta PICOC

\begin{tabular}{|c|c|c|}
\hline $\mathrm{P}$ & Población & Pacientes hospitalizados \\
\hline $\mathrm{I}$ & Intervención & $\begin{array}{l}\text { Desinfección pasiva con el uso de protectores de } \\
\text { puertos desinfectantes en los conectores sin aguja } \\
\text { de los catéteres venosos centrales }\end{array}$ \\
\hline $\mathrm{C}$ & Comparación & No hay comparación \\
\hline $\mathrm{O}$ & Resultado & $\begin{array}{l}\text { Disminución en la incidencia de las bacteriemias } \\
\text { asociadas al catéter venoso central }\end{array}$ \\
\hline $\mathrm{C}$ & Contexto & $\begin{array}{l}\text { Personas con catéter venoso central que reciben } \\
\text { atención para la salud a nivel intrahospitalario, en } \\
\text { las que se haya utilizado protectores de puerto } \\
\text { desinfectantes }\end{array}$ \\
\hline
\end{tabular}

Se optó por no realizar comparación con el método de desinfección activa por fricción, debido a que ya está establecido en la literatura el cuestionamiento sobre la efectividad de este tipo de desinfección, porque no existe consenso con respecto al tiempo de fricción mínimo efectivo y al tipo de desinfectante. Ante esta situación, nuevas investigaciones proponen el uso de protectores puerto desinfectantes como una opción más costo-efectiva para la desinfección de los puertos de acceso de los accesos vasculares. Por tanto, esta revisión se centró en la búsqueda de evidencia acerca de la efectividad de la desinfección pasiva.

En esta línea, se realizó una búsqueda de estudios científicos publicados en formato electrónico en las bases de datos Pubmed, Medline, Cochrane Library y Science Direct; debido a que estas corresponden a bases conocidas por contener un alto porcentaje de los artículos publicados. Tales bases fueron consultadas durante los meses de diciembre del año 2018, enero y febrero del año 2019. Al respecto, la búsqueda se centró en identificar estudios que correspondieran a ensayos: clínicos aleatorizados, cohorte longitudinal, revisiones sistemáticas y metaanálisis. Cabe mencionar que la revisión se limitó a artículos publicados en idioma inglés y español.

Para la búsqueda de artículos, dos revisores (CL y VB) se basaron en las combinaciones de la palabra clave con varios descriptores y utilizaron el booleano AND. Las combinaciones empleadas fueron: "Desinfección and Protectores Puerto Desinfectantes", "Desinfección and Puerto con antiséptico", "Desinfección and Bacteriemia relacionada al catéter", "Disinfection and Needleless connector", "Disinfection and Catheter cap", "Disinfection and Needleless access port", "Disinfection and Disinfecting cap", "Disinfection and Antimicrobial cap", "Disinfection and Hub protection cap", "Disinfection and Port protector", "Disinfection and Antiseptic barrier cap", "Disinfection and Passive port protector", "Disinfection and Catheter -related bacteremia" y "Disinfection and Central line associated bloodstream infections (CLABSI)".

Aunado, se incluyeron los artículos que cumplieron los siguientes criterios de inclusión: (1) estudios realizados con pacientes hospitalizados, (2) uso de protectores puertos desinfectantes como medio de desinfección pasiva de los conectores sin aguja del catéter venoso central y (3) reporte de disminución del riesgo de bacteriemias asociado con el uso de protectores puerto desinfectantes. 
Además, se excluyeron los artículos que fueron (1) previos al año 2008, (2) estudios realizados en ámbitos no hospitalarios e (3) investigaciones relacionadas con la desinfección manual de los conectores sin aguja del catéter venoso central.

La preselección la realizaron dos revisores (CL y VB) mediante la lectura del título y resumen del artículo como estrategia para determinar los estudios potencialmente elegibles. Se tomó en consideración que el resumen de cada artículo incluyera los elementos de relevancia expuestos claramente en este apartado, tales elementos son: el objetivo de la investigación, la metodología, los resultados y las conclusiones principales. Los artículos que no cumplieron con los criterios de inclusión, fueron eliminados de la lista; además, la identificación de los artículos duplicados se realizó manualmente.

Posteriormente, se procedió a la selección, se obtuvo el texto completo del artículo y se realizó una primera lectura para confirmar que el estudio cumpliera todos los criterios de inclusión. En este sentido, todos los revisores evaluaron independientemente el texto completo de cada estudio, para hacer la selección final de artículos relevantes por incluir. Finalmente, los estudios seleccionados fueron revisados por tres revisores para asegurar que cumplieran con los criterios de inclusión. Los resultados de la búsqueda se presentan en un Diagrama de Flujo PRISMA $2009^{19}$, en su versión en español (Figura 1).

Para la extracción de los datos de los artículos, se confeccionó una tabla de Evidencia, en la cual se recopilaron los siguientes datos: título del estudio, autores, revista de publicación, año de publicación, tipo y número de estudios incluidos, objetivo principal, resultados clínicos medidos, principales hallazgos y conclusiones principales. Asimismo, los datos fueron extraídos y verificados por CL, JR, HN, GO, WI. Además, los desacuerdos fueron discutidos por el autor de la extracción y el autor de la verificación; sobre ello, cabe mencionar que no fue necesario el juicio del tercer autor para llegar a un acuerdo.

\section{Resumen de Evidencia}

\section{Cantidad de investigaciones disponibles}

Un total de 2479 artículos fueron identificados en la búsqueda en las bases de datos seleccionadas. Posterior a la eliminación de los estudios duplicados, se realizó la evaluación de 1622 artículos a partir del título y el resumen, de los cuales se excluyeron 1563 artículos. Los 59 artículos restantes fueron evaluados mediante la lectura del texto completo. De estos artículos potencialmente relevantes, se excluyeron 56 debido por diversas razones, mientras que los 3 restantes, al cumplir con los criterios de inclusión, fueron contenidos en la revisión.

Se encontraron tres revisiones sistemáticas relacionadas con desinfección pasiva de los CSA y las BACVC; de las cuales dos realizaron meta-análisis (Tabla 2). Durante la búsqueda en las bases de datos, se evidenció que no se han publicado estudios de cohorte longitudinal ni ensayos clínicos aleatorizados relacionados con el tema.

Posterior a la lectura del texto completo de los artículos seleccionados, se utilizaron las listas de chequeo para revisiones sistemáticas y meta-análisis del Joanna Briggs Institute para realizar la evaluación crítica de la calidad metodológica de los estudios ${ }^{20}$. 
Figura 1. Diagrama de Flujo PRISMA 2009 (Versión en español)
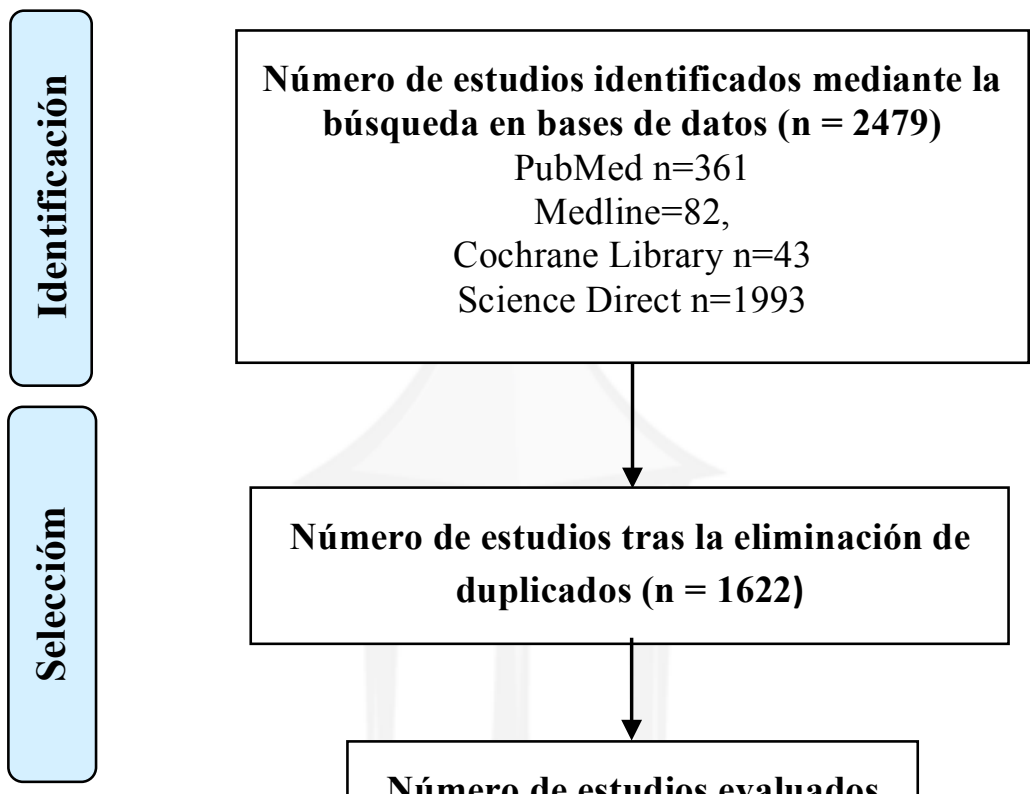

Número de estudios evaluados en título y resumen

$$
(\mathbf{n}=\mathbf{1 6 2 2})
$$

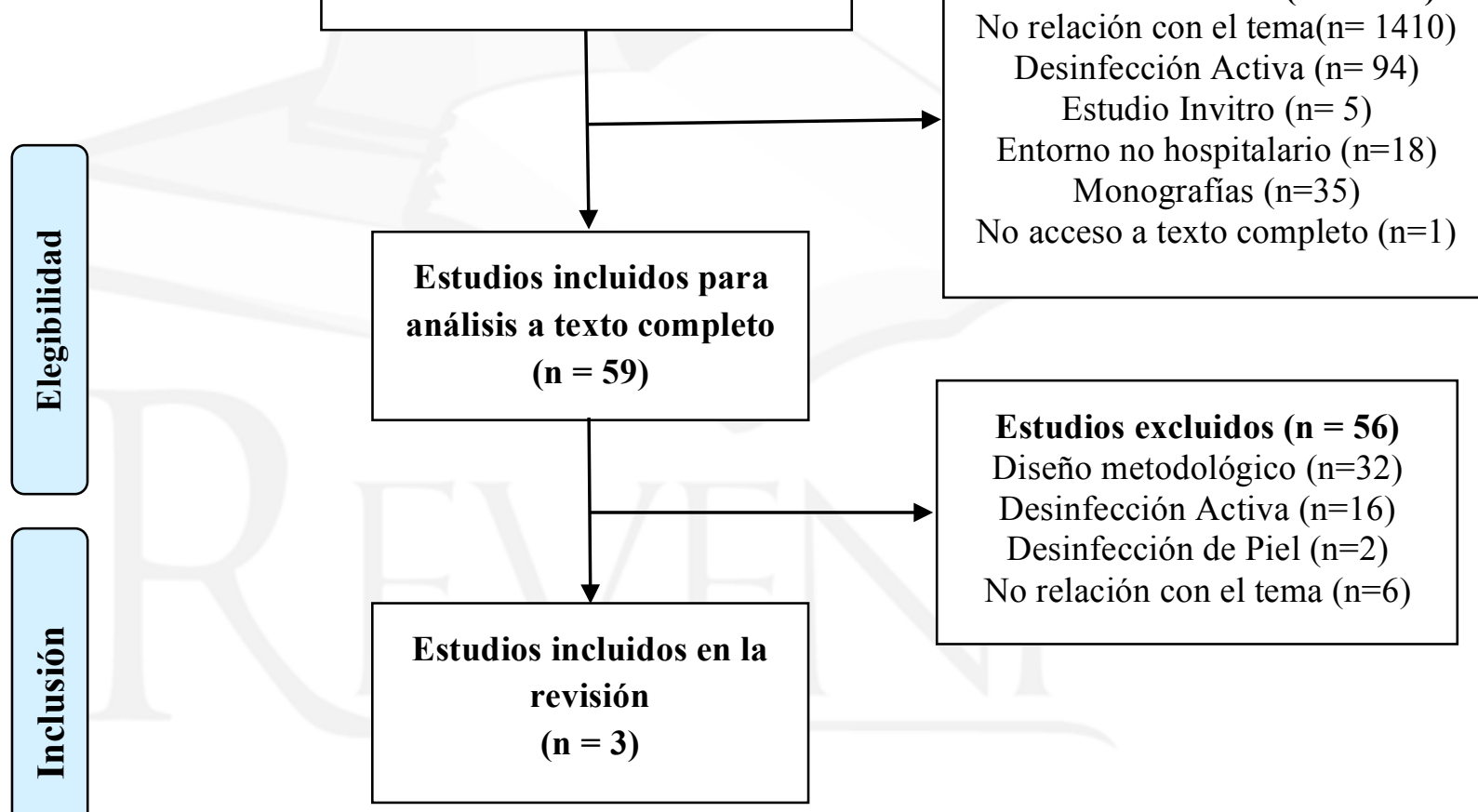


Tabla 2. Características de los artículos seleccionados

\begin{tabular}{|c|c|c|c|}
\hline $\begin{array}{c}\text { Título, autores, } \\
\text { revista y año de publicación, } \\
\text { entorno, base de datos }\end{array}$ & $\begin{array}{l}\text { Tipo y número de } \\
\text { estudios incluidos }\end{array}$ & Objetivo principal & Resultados clínicos medidos \\
\hline $\begin{array}{l}\text { Desinfección de los Conectores } \\
\text { sin Aguja, Revisión Sistemática } \\
\text { de la Evidencia Clínica } \\
\text { (Disinfection of Needleless } \\
\text { Connector Hubs: Clinical } \\
\text { Evidence } \\
\text { Systematic Review) } \\
\text { Nancy Moureau } \\
\text { Julie Flynn } \\
2015 \\
\text { Nursing Research and Practice }\end{array}$ & $\begin{array}{lr}140 & \text { estudios } \\
\text { relacionados con la } \\
\text { desinfección }\end{array}$ & $\begin{array}{l}\text { Evaluar la literatura } \\
\text { actual relacionada } \\
\text { con la desinfección } \\
\text { de los conectores sin } \\
\text { aguja para establecer } \\
\text { recomendaciones. } \\
\text { que promuevan el } \\
\text { acceso aséptico, } \\
\text { reduciendo el riesgo } \\
\text { de infección para el } \\
\text { paciente. }\end{array}$ & $\begin{array}{l}43 \text { artículos relacionados con } \\
\text { agentes desinfectantes y } \\
\text { dispositivos } \\
24 \text { artículos sobre conectores } \\
\text { sin aguja } \\
38 \text { artículos relacionados con } \\
\text { fuentes de contaminación y } \\
\text { porque desinfectar } \\
35 \text { artículos sobre educación y } \\
\text { cumplimiento de las } \\
\text { recomendaciones para } \\
\text { prácticas de desinfección }\end{array}$ \\
\hline $\begin{array}{l}\text { BASE DE DATOS: Pubmed, } \\
\text { Medline, Science Direct }\end{array}$ & & & \\
\hline $\begin{array}{l}\text { Los tapones de barrera } \\
\text { antisépticos son efectivos en la } \\
\text { reducción de las bacteriemias } \\
\text { asociadas a catéter venoso } \\
\text { central: Una revisión } \\
\text { sistemática y meta-análisis } \\
\text { (Antiseptic barrier cap effective in } \\
\text { reducing central line-associated } \\
\text { bloodstream infections: A } \\
\text { systematic review and meta- } \\
\text { analysis) } \\
\text { Anne Voor in't holt, Onno } \\
\text { Helder, Margreet Vos, Laura } \\
\text { Schafthuizen }\end{array}$ & $\begin{array}{l}9 \text { artículos se } \\
\text { incluyeron en la } \\
\text { revisión sistemática y } \\
\text { siete de estos se } \\
\text { utilizaron en el meta- } \\
\text { análisis } \\
\text { TIPO: } 9 \text { estudios } \\
\text { quasiexperimentales } \\
\text { de antes y después }\end{array}$ & $\begin{array}{l}\text { Comparar los efectos } \\
\text { del uso de tapones de } \\
\text { barrera antisépticos y } \\
\text { la desinfección } \\
\text { manual en la } \\
\text { incidencia de las } \\
\text { bacteriemias } \\
\text { asociadas al catéter }\end{array}$ & $\begin{array}{l}9 \text { estudios reportaron la tasa de } \\
\text { bacteriemias asociadas a } \\
\text { catéter venoso central } \\
4 \text { estudios reportaron el } \\
\text { cumplimiento en el uso de los } \\
\text { tapones de barrera antisépticos }\end{array}$ \\
\hline
\end{tabular}




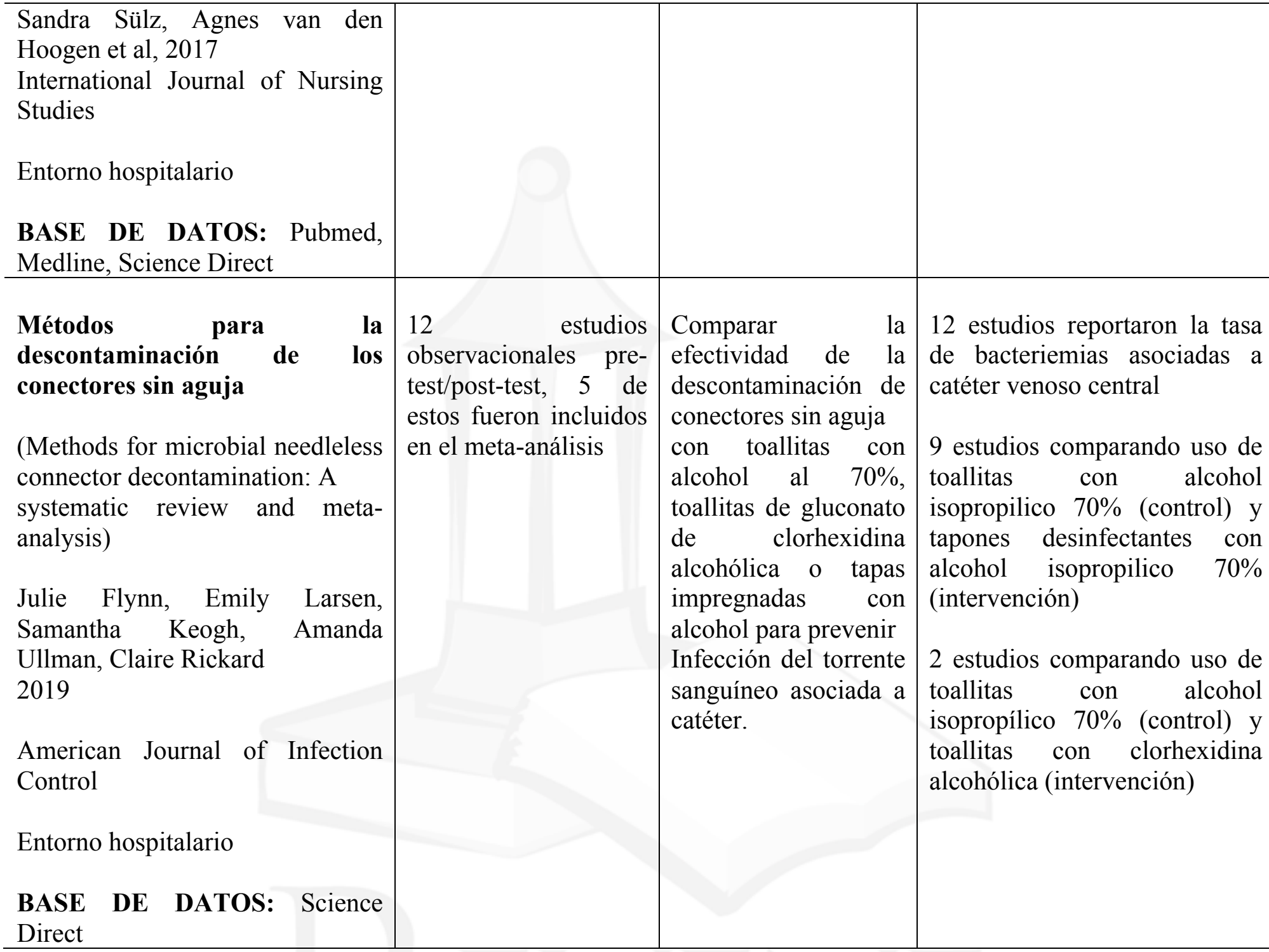

\section{RESULTADOS SEGÚN PREGUNTAS DE INVESTIGACIÓN}

¿Cuál es el efecto del uso de protectores puerto desinfectantes en los conectores sin aguja, para la disminución de las bacteriemias asociadas a catéteres venosos centrales en pacientes hospitalizados?

La revisión sistemática de Moureau y Flynn ${ }^{18}$ concluye que los tapones para desinfección pasiva reducen las suposiciones en el campo y proveen a los trabajadores en salud un punto de referencia sobre uso y reducción de la contaminación. Las autoras señalan que los tapones para desinfección colocados en todos los puertos de acceso, eliminan los problemas de factores humanos, que ocurren cuando los clínicos no recuerdan llevar los suministros 
de desinfección necesarios al lado de la cama o, incluso, cuando no recuerdan realizar el acto de desinfección antes de cada acceso.

Ahora bien, en la revisión sistemática desarrolla por Voor in ' $t$ holt et $\mathrm{al}^{21}$, los autores refieren que encontraron evidencia acerca de que los protectores de puerto desinfectantes comparados con la desinfección manual de los CSA, se asocian con una disminución en el riesgo de incidencia de las BACVC, incluso, cuando excluyeron dos de los estudios seleccionados que presentaban baja calidad metodológica y posible conflicto de interés.

Para el desarrollo del metaanálisis, los autores incluyeron siete de nueve estudios seleccionados, lo cual corresponde a un 77,8\%. El IRR de los estudios individuales fue desde 0.14 hasta 0.76 . Tres de estos siete estudios (42.9\%) no mostraron un resultado estadísticamente significativo al comparar el tapón desinfectante con el cuidado regular. La relación tasa de incidencia (IRR) combinado mostró que el tapón desinfectante fue efectivo en la reducción de las bacteriemias asociadas a catéter, ya que se obtuvo un IRR $=0.59$, un intervalo de confianza (IC) del $95 \%=0.45-0.77$ y un valor de $\mathrm{P}<0.001$. Al excluir los estudios de baja calidad metodológica $(\mathrm{n}=2)$, el IRR aumentó a $0.66(95 \%$ CI $=0.53-0.83)$. No obstante, refieren que la asimetría de los gráficos de embudo indicó sesgo de publicación ${ }^{21}$.

Asimismo, Voor in 't holt et $\mathrm{al}^{21}$ reportaron una tasa media de cumplimento del uso de los tapones de barrera antiséptica de un $82,5 \%$, la cual es alta si se compara con las tasas de cumplimiento de la desinfección manual. Asimismo, hicieron la salvedad de que muchos de los estudios no exponen claramente el método con el cual valoraron este cumplimiento y casi la mitad de los estudios incluidos no describieron la tasa de cumplimiento posterior a la implementación de los protectores puerto desinfectantes. No obstante, señalan que la implementación del uso de estos dispositivos en la práctica diaria es factible.

Finalmente, Flynn et al $^{22}$ concluyeron que estudios no randomizados evidencian que tanto las toallitas con clorhexidina alcohólica como la desinfección pasiva con tapones impregnados con AIP al 70\% se asocian con una incidencia de BACVC significativamente más baja que las toallitas con AIP al 70\% (IRR,0.43; IC 95\%, 0.280.65). Sin embargo, resaltan que existe una falta de evidencia de alta calidad para confirmar cuál es el mejor método de desinfección al colocar y mantener un dispositivo de acceso vascular. Con la disponibilidad de novedosos métodos, se necesitan con urgencia ensayos clínicos aleatorizados que establezcan cuál es el método de descontaminación óptimo para prevenir las BACVC.

¿Cuál es el agente desinfectante de uso más común en la desinfección pasiva de los puertos de acceso de los catéteres venosos centrales?

Moureau y Flynn ${ }^{18}$ refieren que la investigación sobre desinfección incluye varias formas de protección pasiva antimicrobiana de los puertos de acceso de los CVC, mediante el uso de tapones con alcohol al 70\%, dentro de los que se pueden mencionar: el SwabCap, Curos Port Protector, EffectIV-Cap y el DualCap. En este sentido, numerosos estudios han demostrado efectividad clínica consistente con el uso único de tapones desinfectantes de alcohol al 70\%, sin embargo, las fuentes corresponden a publicaciones con bajo nivel de evidencia científica. 
Asimismo, mencionan que los tapones con clorhexidina alcohólica también son efectivos en la prevención de la contaminación y la completa desinfección de la superficie de los CSA; no obstante, su efecto aún no ha sido tan ampliamente estudiado, debido a que no se encuentran disponibles comercialmente en diversos países ${ }^{18}$.

Flynn et $\mathrm{al}^{22}$ identificaron que la desinfección activa de los CSA con toallitas de clorhexidina alcohólica o la desinfección pasiva de los mismos con tapones impregnados de AIP al 70\%, se asocia con una disminución significativa en el riesgo de desarrollar una BACVC; en comparación con el uso de toallitas con AIP al 70\%. En el desarrollo del meta-análisis, se asoció, con una estimación muy precisa del efecto, que el uso de toallitas con clorhexidina alcohólica; en comparación con las toallitas con AIP al 70\% se asocia con dos tercios menos de riesgo de desarrollar una BACVC (IRR, 0.28; 95\% IC, 0.20-0.39). Adicionalmente, los tapones impregnados con AIP al 70\% fueron asociados con menos de la mitad del riesgo de BACVC que las toallitas con AIP al 70\% (IRR, 0.43; 95\% IC, 0.28-0.65). Estos resultados sugieren que, a pesar de que el uso de toallitas con alcohol es generalizado, estos productos son probablemente inadecuados para la descontaminación de los CSA.

No obstante, los autores aclaran que, a pesar de que los resultados del meta-análisis fueron positivos, es necesario que se realicen ensayos clínicos aleatorizados con un tamaño de muestra suficientemente grande para confirmar la causalidad. Asimismo, aunque el uso de la clorhexidina como agente desinfectante para los CSA se ha incrementado debido a estudios que han concluido que su uso es superior al alcohol en la prevención de infecciones y que tiene una actividad de descontaminación prolongada, recalcan que no existe evidencia suficiente de que esto resulte en menos $\mathrm{BACVC}^{22}$.

¿Cuál es la efectividad del uso de los protectores puertos desinfectantes en los conectores sin aguja de los catéteres venosos centrales en la disminución de los costos económicos asociados a la BACVC?

Moureau y Flynn ${ }^{18}$ mencionan un estudio en el cual se reportó una disminución del 50\% en las BACVC y un ahorro de 464440 dólares por año, después de implementar el uso de tapones desinfectantes con alcohol.

Al respecto de los costos, Voor in ' $t$ holt et $\mathrm{al}^{21}$, refieren que todos los estudios que describen los costos concluyen que el uso de tapones de barrera antiséptica ahorra costos; es decir, los costos asociados al manejo de las BACVC superan el costo de utilizar el dispositivo. No obstante, aclaran que la interpretación de estas aseveraciones debe ser cautelosa, debido a que las estimaciones de ahorro neto pueden verse afectadas por escala utilizada para calcularlos y pueden variar según la idiosincrasia del centro.

Flynn et $\mathrm{al}^{22}$ mencionan que, a pesar de que se ha descrito una reducción de las BACVC con la implementación de dispositivos de desinfección pasiva, estos todavía no son ampliamente utilizados; en tal sentido, plantean que una posible explicación podría estar relacionada con el costo de estos productos.

En línea con lo anterior, los autores exponen un ejemplo que detalla que el costo de toallitas con alcohol y con clorhexidina alcohólica es muy bajo $(\$ 0.01-\$ 0.02)$, en comparación con un tapón desinfectante impregnado con alcohol que puede ser 17 veces más costoso. Entonces, en el caso de un paciente agudamente enfermo, este puede requerir por día más de 20 productos para desinfectar, lo cual genera un costo mínimo que oscila entre los $\$ 0.29$ al utilizar toallitas con alcohol al $70 \%$ y entre los $\$ 3.33$ al usar de tapones desinfectantes. Posteriormente, contrastan dichos costos con los gastos asociados al manejo y la atención de las BACVC que puede oscilar en un 
rango de $\$ 17896$ hasta $\$ 94879$; lo cual sugiere que un desembolso inicial mayor para realizar una compra de productos para desinfección de los CSA podría ser costo efectivo.

\section{Riesgo de sesgo y limitaciones}

Esta revisión no incluyó revisión de fuentes manuales ni literatura gris; por lo cual es posible que información pertinente al tema haya sido excluida. Asimismo, la búsqueda de información solo incluyó los idiomas inglés y español.

La principal limitación de este estudio es la baja cantidad de estudios incluidos, debido a que no se encontró, durante la búsqueda en las bases de datos, estudios de alta calidad metodológica, como ensayos clínicos aleatorizados o estudios de cohorte.

\section{CONCLUSIONES}

A partir de la presente revisión rápida de literatura, se puede confirmar que la evidencia científica existente hasta el momento respalda la efectividad del uso de los protectores puerto desinfectantes en los CSA para la reducción de las BACVC. Además, el uso de estos podría considerarse como una medida costo efectiva; sin embargo, debe tomarse en cuenta que tales estimaciones deben contextualizarse desde cada centro clínico. No obstante, vale la pena recalcar que es necesario el desarrollo de investigaciones aleatorizadas que den mayor sustento y claridad a la evidencia sobre el efecto de estos dispositivos en la disminución de las BACVC, dado que las investigaciones actuales no son de alta calidad y, por ende, este efecto podría desestimarse o estar subestimado.

También, es necesario un mayor conocimiento en relación con cuál es el mejor método para la desinfección de los CSA, ya que, aun cuando actualmente, el alcohol isopropílico al 70\%, en presentación de toallitas es el agente más utilizado, podría no ser el mejor y más efectivo. Situación que daría pie a la aparición en el escenario de los protectores puerto desinfectantes como una alternativa novedosa y costo-efectiva. Asimismo, faltan más estudios que permitan determinar con claridad los efectos de la clorhexidina alcohólica como agente desinfectante en los CSA.

\section{CONFLICTO DE INTERÉS}

Los autores declaran que no tienen conflicto de tipo personal, comercial, académico, político o financiero.

\section{REFERENCIAS BIBLIOGRÁFICAS}

1. Mesiano E, Hamann E. Bloodstream infections among patients using central venous catheters in intensive care units. Rev Latino-am Enfermagem. 2007; 15(3): 453-459. DOI: http://dx.doi.org/10.1590/S0104$\underline{11692007000300014}$

2. Ramírez M. Septicemia asociada a catéter venoso central. Rev Cl EMed UCR. 2012; 2(12): 5-18. Disponible en: https://revistas.ucr.ac.cr/index.php/clinica/article/download/10426/9791/ 
3. Mandell G, Bennett J, Dolin R. Enfermedades Infecciosas, Principios y Práctica. 8va Edición. Barcelona: Elsevier; 2015.

4. Padrón-Ruiz OM, Ojeda N, Morales L, Rodríguez A. Infección relacionada con catéter venoso. Rev Española de Anestesiología y Reanimación. 2013; 60(4): 215-225. DOI: http://dx.doi.org/0.1016/j.redar.2012.09.007

5. Pages J, Hazera P, Mégarbane B, Du Cheyron D, Thuong M, Dutheil J, et al. Comparison of alcoholic chlorhexidine and povidone-iodine cutaneous antiseptics for the prevention of central venous catheter-related infection: a cohort and quasi-experimental multicenter study. Intensive Care Med. 2016; 42: 1418-1426. DOI: http://dx.doi.org/10.1007/s00134-016-4406-4

6. O’Grady NP, Alexander M, Burns LA, Dellinger E, Garland J, Heard S, et al. Guidelines for the prevention of intravascular catheter-related infections. Am J Infect Control. 2011; 39: 1-34. DOI: http://dx.doi.org/10.1016/j.ajic.2011.01.003

7. Wisplinghoff H, Bischoff T, Tallent S, Seifert H, Wenzel R, Edmond M. Nosocomial bloodstream infections in US hospitals: Analysis of 24,179 cases from a prospective nationwide surveillance study. Clin Infect Dis. 2004; 39: 309-17. DOI: http://dx.doi.org/10.1086/421946

8. Coello R, Charlett A, Ward V, Wilson, J. Pearson, A. Sedgwick, J. et al. Device related sources of bacteraemia in English hospitals - opportunities for the prevention of hospital-acquired bacteremia. J Hosp Infect. 2003; 53: 46-57. DOI: http://dx.doi.org/10.1053/jhin.2002.1349

9. $\mathrm{Hu} \mathrm{K}$, Veenstra D, Lipsky BA, Saint S. Use of maximal sterile barriers during central venous catheter insertion: clinical and economic outcomes. Clin Infect Dis. 2004; 39: 1441-1445. DOI: https://doi.org/10.1086/425309.

10. Allegranzi B, Bagheri S, Combescure C, Graafmans W, Attar H, Donaldson L, et al. Burden of endemic health-care-associated infection in developing countries: systematic review and meta-analysis. Lancet. 2011; 377: 228-41. DOI: https://doi.org/10.1016/S0140-6736(10)61458-4

11. Marschall J, Mermel LA, Classen D, Arias KM, Podgorny K, Anderson DJ, et al. Strategies to prevent central line-associated bloodstream. Infect Control Hosp Epidemiol. 2008; 29(1): 22-30. DOI: http://dx.doi.org/10.1086/591059

12. Merrill KC, Sumner S, Linford L, Taylor C, Macintosh C. Impact of universal disinfectant cap implementation on central line associated bloodstream infections. Am J Infect Control. 2014; 42: 1274-1277. DOI: http://dx.doi.org/10.1016/j.ajic.2014.09.008

13. Casey AL, Burnell S, Whinn H, Worthington T, Faroqui MH, Elliott TS. A prospective clinical trial to evaluate the microbial barrier of a needleless connector. Journal of Hospital Infection. 2007; 65: 212-218. DOI: http://dx.doi.org/10.1016/j.jhin.2006.09.029 
14. Ryder MA. Catheter-related infections: it's all about biofilm. Top Advanced Pract Nurs eJ. 2005; 5(3). Disponible en: https://www.medscape.com/viewarticle/508109

15. Doellman D. The role of technology in reducing risks associated with CRBSI. Ivera Medical Corporation. Disponible en: http://www.curos.com/wp-content/uploads/CRBSI-White-Paper_DarcyDoellman.pdf

16. Menyhay SZ, Maki DB. Disinfection of needless catheter connectors and access ports with alcohol may not prevent microbial entry: the promise of a novel antiseptic-barrier cap. Infect Control Hosp Epidemiol. 2006; 17: 23-7. DOI: http://dx.doi.org/10.1086/500280

17. Oto J, Imanaka H, Konno M, Nakataki E, Nishimura M. A prospective clinical trial on prevention of catheter contamination using the hub protection cap for needleless injection device. Am J Infect Control. 2011; 39(4): 309-313. DOI: http://dx.doi.org/10.1016/j.ajic.2010.06.016

18. Moureau N, Flynn J. Disinfection of needleless connector hubs: clinical evidence systematic review. Nurs Res Pract. 2015; 796-762. DOI: http://dx.doi.org/10.1155/2015/796762

19. Moher D, Liberati A, Tetzlaff J, Altman DG, The PRISMA Group. Preferred Reporting Items for Systematic Reviews and Meta-Analyses: The PRISMA Statement. PLoS Med. 2009; 6(7): e1000097. DOI: https://doi.org/10.1371/journal.pmed.1000097

20. Joanna Briggs Institute. Critical Appraisal tools for use in JBI Systematic Reviews. Checklist for Systematic Reviews and Research Syntheses. 2017. Disponible en: http://joannabriggs.org/research/critical-appraisaltools.html

21. Voor in t holt A, Helder O, Vos M, Schafthuizen L, Sülz S, Van den Hoogen, et al. Antiseptic barrier cap effective in reducing central line-associated bloodstream infections: A systematic review and meta-analysis. Int J Nurs Stud. 2017; 69: 34-40. DOI: http://dx.doi.org/10.1016/j.ijnurstu.2017.01.007

22. Flynn J, Larsen E, Keogh S, Ullman A, Rickard C. Methods for microbial needleless connector decontamination: A systematic review and meta-analysis. Am J Infect Control. 2019; 000: 1-7. DOI: http://doi.org/10.1016/j.ajic.2019.01.002 